\title{
El desarrollo de la categorización: Perspectivas tradicionales y contemporáneas ${ }^{2}$
}

\author{
The development of categorization: \\ traditional and contemporary perspectives
}

\section{Resumen}

La categorización como un proceso gracias al cual organizamos y damos coherencia al mundo, es objeto de estudio y de controversias dentro de la tradición en psicología. Específicamente, las características de la categorización en el desarrollo, son tema de discusiones que cobran más interés hoy en día. En este artículo recogemos artículos de los más importantes investigadores en este tema, para mostrar las perspectivas tradicionales desde el debate forma-función, y las nuevas perspectivas desde la cognición corporizada, que ven la categorización, al igual que otros procesos cognitivos, como producto de la relación perceptuomotora con el mundo. Veremos qué aportes a la categorización nos ofrecen estas visiones y cuáles son las preguntas que quedan pendientes para la investigación en esta área.

Palabras clave: categorización, desarrollo, debate forma-función, cognición corporizada.

\begin{abstract}
Categorization as a process to give coherence and organize the world is subject of studies and controversies in the field of psychology. Specifically, the features of the categorization in development are topics of discussions that are relevant nowadays. This paper collects the most important findings in this topic to show the traditional perspectives of the debate shape-function, and the new perspectives of embodied cognition. These see the categorization, and also other cognitive processes, as a result of the relation "perceptuo-motor" with the world. This paper shows the contributions that these visions give to categorization and the outstanding questions for research in this area.
\end{abstract}

Keywords: categorization, development, shape-function debate, embodied cognition.

\section{Recibido el el 14 de septiembre de 2011 y aprobado el 10 de octubre de 2011}

1 María Clara Garavito, psicóloga, docente de UNIMINUTO. Angie Bohórquez, Wendy Beltrán, Jorge Benítez, Nubia Galindo y Luisa Saavedra son estudiantes de psicología de UNIMINUTO.

2 Este artículo es producto del trabajo y las discusiones en el Semillero de Investigación: "desarrollo de la categorización". Dicho semillero está adscrito al grupo de investigación "Estudios sobre psicología básica y aplicada para el desarrollo social" del programa de psicología de UNIMINUTO. El semillero se encuentra a cargo de la docente María Clara Garavito. 


\section{Introducción}

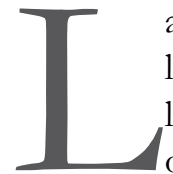

a categorización es un proceso psicológico fundamental, que da cuenta de la manera en que los seres humanos organizamos y damos coherencia al mundo. En torno a este proceso giran diferentes discusiones, centradas en preguntas como por ejemplo qué tipos de rasgos (si las formas o las funciones) tenemos en cuenta los seres humanos al momento de categorizar un objeto, si las categorías suponen una representación prototípica del objeto o si ésta no es necesaria y cuál es el papel que cumplen la percepción y la acción en la categorización. Estás preguntas han llevado a cuestionarse si en el desarrollo la categorización evoluciona siguiendo las pautas de otros procesos cognitivos, y por ende, si realmente podemos hablar en los mismos términos respecto a la categorización en todos los momentos de la vida. Enfocados en el desarrollo, encontraremos una perspectiva que responde a los diferentes debates teniendo en cuenta el papel de la percepción y la acción en el momento de categorizar. Esta perspectiva que se concentra en una cognición situada y corporizada, según la cual el desarrollo de la categorización no es más que el producto de la experiencia perceptuo-motora con el mundo. Reconocemos los objetos porque hemos tenido experiencia con ellos, hemos interactuado con ellos, por lo que nuestra experiencia es una experiencia corporal con el mundo. Desde aquí nos preguntamos ¿cuál es el futuro de las discusiones en torno al desarrollo de la categorización? Este trabajo recoge algunos artículos representativos de los autores más destacados en estas discusiones. La elección de éstos artículos entre la cantidad de bibliografía que estos autores presentan anualmente, es producto de una revisión en la que consideramos que dichos artículos exponen las distintas teorías de manera clara y con ejemplos interesantes. El enfoque de nuestro trabajo es hacer una aproximación, a través de éstas distintas perspectivas, sobre el desarrollo de la categorización, y qué nos pueden aportar para el desarrollo de futuras investigaciones.

\section{La categorización en el desarrollo}

Según los psicólogos del desarrollo como Jean Piaget, cuando nacemos nos enfrentamos a un mundo que se presenta rico en estímulos y aparentemente caótico, por lo que desde ese momento comenzamos a darle un orden. Piaget (1972) mostró evidencia según la cual, ésta organización se explica a través de la relación sensorio-motora con el mundo. Inicialmente, el entorno está constituido por cuadros que se mueven y que a la vez son inconsistentes; los objetos en sí mismos, con unas propiedades y relaciones físicas con otros objetos, son una construcción que se da en el desarrollo.

El periodo sensorio-motor, la primera etapa del desarrollo cognitivo según Piaget, se caracterizará por la construcción, no sólo de la noción de objeto como una de las grandes categorías de 
acción, sino que también las de espacio, tiempo y causalidad a partir de las cuales emergen las demás categorías (Piaget, 1979). El desarrollo consistirá en la progresiva extensión de estas categorías ligadas a la acción y la percepción hacia categorías que se denominarán representativas (Piaget, 1961).

Muchas investigaciones posteriores a las de Piaget, se han enfocado a la explicación de la categorización de los artefactos, aquellos objetos creados por los seres humanos que hacen parte de nuestra vida cotidiana. La divergencia sobre cómo categorizamos es evidente, y en la actualidad podemos ver latentes algunas discusiones que comenzaron hace más de veinte años, siendo algunos de sus más importantes representantes Ameel, Malt \& Storms (2008), Bloom (2007), Malt \& Sloman (2007) y Matan \& Carey (2001). Estas discusiones han estado enmarcadas en lo que se llama el debate forma-función: algunos autores consideran que para categorizar tenemos en cuenta los rasgos perceptuales salientes o, en otras palabras, la forma de los objetos (por ejemplo algo es una mesa porque tiene una superficie plana y cuatro patas); otros autores consideran que lo que tenemos en cuenta es el para qué sirve el artefacto -o función- (por ejemplo que es una mesa porque sirve para poner objetos en su superficie, cf. Cuenca \& Ruiz, 2004). Desde la perspectiva de la función se crearon otras variantes, como la de la intención del creador (Bloom, 2007), según la cual lo que los seres humanos tenemos en cuenta al categorizar es el para qué fue creado el artefacto.

Pero la investigación sobre la categorización de artefactos no se limita al debate forma-función. En la actualidad han surgido nuevas maneras de entender la categorización, a partir de perspectivas del desarrollo desde las teorías de cognición situada y corporizada, específicamente la perspectiva desde la teoría de los sistemas dinámicos que impulsaron Thelen \& Smith (1994). Desde esta visión, la categorización es un proceso siempre ligado a la experiencia sensorio-motora. El actuar con los objetos cotidianos hace que la per- cepción de los mismos se modifique; la acción y la percepción se entienden entonces como un mismo fenómeno. La actuación supone chupar, morder, coger, voltear y todas las acciones que podamos hacer con un objeto; estas son las que nos permiten identificar tanto rasgos perceptuales como funcionales con los cuales decimos que un objeto pertenece a determinada categoría. Desde aquí, la categorización nunca deja de ser sensorio-motora, porque precisamente lo que nos permite ser expertos en categorías y decir, con toda propiedad que un objeto pertenece a una de ellas, es nuestra constante experiencia con el mundo que es siempre cambiante (Smith \& Sheya, 2010).

Para poder abordar las nuevas perspectivas sobre categorización, desde la propuesta de una cognición ligada a lo sensorio-motor, tenemos que remontarnos a las teorías tradicionales, y así entender el rumbo que ha tomado la investigación en estos temas. Por lo tanto, a continuación, daremos cuenta inicialmente de aproximaciones a la categorización desde las visiones tradicionales en el debate forma-función desde algunos de sus autores más representativos para posteriormente mostrar los avances desde las perspectivas de sistemas dinámicos.

\section{El debate forma-función en el desarrollo}

Ameel, Malt, \& Storms, (2008), como partidarios de la categorización a partir de la forma, investigan cómo el desarrollo de este proceso continúa luego de la adquisición del léxico temprano. Ellos encuentran que el mapeo rápido o fast mapping es el proceso que permite entender la categorización temprana (como una especie de escáner que recoge rápidamente los rasgos perceptuales necesarios para decir que, por ejemplo, un objeto es una silla). De esta manera, cuando un niño de dos años tiene la categoría establecida, el mapeo permite incluir mayor cantidad de objetos en esta (Clark, 1993, citado por Ameel et al., 2008). 
El léxico tardío (entre los cinco y catorce años) implicará un proceso de categorización más complejo, que permite ubicar dentro de una categoría algunos especímenes que no parecen compartir muchos rasgos con los miembros típicos, al mismo tiempo que permite excluir otros. Por otra parte, vale la pena preguntarse cómo continúa la trayectoria de aprendizaje conceptual en relación con el aprendizaje de los rasgos perceptuales, luego de los primeros años de aprendizaje lexical.

Tres preguntas son básicas en la investigación de estos autores: (1) ¿Luego de los primeros años de la adquisición del lenguaje continúa evolucionando la manera en que se aprenden los nombres referidos a objetos familiares y concretos? (2) Si es así, ¿cómo evoluciona el aprendizaje de los rasgos perceptuales que determinan que un objeto sea de una categoría, hasta el punto que el significado de las palabras para el niño converja con el significado de las palabras para un adulto? y ¿hasta qué punto puede un único grupo de rasgos explicar los patrones de nombramiento en niños y adultos? Finalmente (3) ¿El desarrollo del uso de palabras es de naturaleza puramente lexical o continúa jugando un papel importante el desarrollo categorial, aún para objetos comunes? (Ameel et al., 2008).

Para tratar de responder a estas preguntas se realizaron tres estudios. En el primero se examinó la evolución del aprendizaje de nombres comunes. Para esto se recolectaron imágenes de 73 contenedores caseros. Estos se seleccionaron teniendo en cuenta la probabilidad de que se nombraran como botella (bottle) o tarro (jar) o que tuvieran propiedades salientes que compartieran con estos dos tipos de contenedores. En otro grupo se usaron 67 imágenes de tazas y platos, teniendo en cuenta la probabilidad de que se les llamara plato (dish), bandeja (plate) o tazón (bowl). Los participantes fueron niños entre los 5 y 14 años. Ellos miraban las imágenes escogidas al azar y nombraban cada una. También se les preguntaba si algún nombre era el mejor o el más natural. Se encontró que los niños hasta los ocho años tendían tanto a sobreextender los nombres (poner el mismo nombre a muchas imágenes que no correspondían) como a sub-extenderlos (en algunos casos solo usaban un nombre para una sola imagen, dejando por fuera otros representantes de la categoría). Estos resultados estarían de acuerdo con la teoría de la categorización de Mervis (1987 citado por Ameel et al., 2008), según la cual lo que cambia en el desarrollo no es la cantidad de rasgos que se tienen en cuenta para categorizar sino la calidad de éstos. Luego de los 8 años, progresivamente se va reorganizando la categoría (que cada vez más tiende hacia el estado normal adulto, aunque en algunos casos los niños mayores sobreextienden o subextienden y en otros no), hasta que se estabiliza alrededor de los catorce años, edad en la que se identificarán todas las figuras del mismo modo en que lo hace un adulto.

En el segundo estudio, se investigó la naturaleza del aprendizaje que tiene lugar en el desarrollo. Se buscaba reportar qué rasgos específicos tienen en cuenta los adultos y los niños de diferentes grupos de edad para poner nombres a las imágenes. Así, luego de presentar imágenes a niños o adultos, se les preguntaba qué rasgos hacían pertenecer a un contenedor a una categoría específica. Se encontraba que los rasgos a los que atendían los participantes variaban en naturaleza entre niños y adultos, aunque esta diferencia iba disminuyendo gradualmente con el tiempo.

Finalmente, el tercer estudio quería mostrar el papel de la función del objeto en el desarrollo lexical. Con esto, Ameel y otros (2008), aunque defienden el desarrollo desde una propuesta de que la categorización está determinada por la forma de los objetos, terminan afirmando que la función es necesaria para la categorización. Por ejemplo, dirán que hasta que los niños no entiendan para qué se usa la ranura en una alcancía, seguirán usándola como una pelota (en el caso de una alcancía en forma de marrano).

Los autores usaron las imágenes de botellas de los estudios anteriores, y niños de edades entre los 8 y 14 años. Se pidió a los niños que miraran las imágenes. Luego se les dijo que pusieran en filas todos los objetos que parecían similares, 
y a continuación se les preguntó por qué ubicaban las imágenes en tales filas. Se encontró que mientras que la explicación de los más pequeños estaba ligada a rasgos, la de los más grandes comenzaba a estar ligada a funciones de los objetos, hasta que la explicación convergía con la de los adultos.

Con estos resultados, Ameel y otros (2008) confirman su hipótesis de que lo que cambia en el desarrollo lexical no se encuentra a nivel de la cantidad sino de la calidad de los rasgos perceptuales que se necesitan para determinar que un objeto pertenece a una categoría. Esta variación en la calidad se daría por una reorganización del sistema de categorización para cada objeto, que comienza a tener en cuenta las funciones de los objetos.

En un estudio previo, desde la tradición de la categorización a partir de la función, se confirmó el papel de esta característica para entender el desarrollo. Matan \& Carey (2001) realizaron tres experimentos para dar cuenta del papel que cumple la información sobre la función original (el para qué fue hecho) y la función actual de un objeto determinado. Según su postura, es la función original, más que la función actual o los rasgos perceptuales, lo que determina que un objeto sea de una categoría y no de otra. Es más, la función actual o los rasgos perceptuales dependerían de la función original, como una estructura de conocimiento que las contiene. Esta estructura ha sido nombrada por Dennet (1987, citado por Matan \& Carey, 2001) "postura del diseño" (design stance). Dicha estructura daría cuenta "de la existencia misma de un artefacto, su función, sus propiedades y su tipo" (Matan \& Carey, 2001, p. 2).

Desde la postura de Dennet, todo artefacto es creado para una función útil. Basándose en dicha función organizamos los rasgos perceptuales y cualquier otra función alternativa y restringimos el tipo de material del que se puede hacer un objeto. Por su parte, Hall (1995, citado por Matan \& Carey, 2001) ha mostrado que para los adultos la función pretendida prima sobre la función actual en el momento de identificar un artefacto como de una categoría. La postura del diseño supone que lo que hace la función pretendida es limitar el proceso mediante el cual tendemos a dar justificaciones sobre la categoría a la que pertenece un artefacto.

La evidencia de otros autores no deja clara la primacía de la función pretendida sobre otras características. Por ejemplo, Malt y Johnson (1992, citados por Matan \& Carey, 2001) señalan que la función pretendida y las propiedades físicas son propiedades importantes en el momento de categorizar, pero no que una se anteponga a la otra. Sin embargo, para Matan y Carey (2001) esta investigación no tiene en cuenta que la postura del diseño no afirma que lo único que tenemos en cuenta es la función pretendida, sino que considera que es ésta la que termina limitando cualquier juicio sobre la categoría a la que pertenece un artefacto. Sin embargo si se ve el desarrollo, podrían identificarse diferencias entre la categorización adulta y la de niños muy pequeños. Los niños pueden dar cuenta de las características funcionales de los objetos, y pueden estar familiarizados con elementos de la postura del diseño, pero esto no indica que ellos actúen dentro de este esquema (Brown, 1989; McCarrell \& Callanan, 1995; Kolstad \& Baillargeon, 1991, citados por Matan \& Carey, 2001). Por ejemplo se ha encontrado que los niños hasta los 6 o 7 años no favorecen siempre la función sobre la forma en la categorización (Gentner, 1978; Keil, 1989; Landau, Smith, \& Jones, 1998, citados por Matan \& Carey, 2001).

Con tres experimentos Matan y Carey buscaron evidencia sobre si la postura del diseño organiza o no la categorización en los niños preescolares. Para esto se adaptó el procedimiento usado por Hall (1995). A los niños se les contaba una historia sobre una persona que hizo un objeto para cumplir una función (ser tetera, por ejemplo) y de otra que lo usaba para otro propósito diferente (para ser regadera). Se preguntaba qué objeto es aquel (si era regadera o tetera). A esta historia se le sumaba una imagen en la cual la mayor parte del objeto estaba oculto, dejando una parte visible que no permitía diferenciar el objeto. 
El primer experimento se hizo con adultos a modo de prueba. Se quería observar si el orden en que se contaban las historias (primero se contaba la función pretendida y luego la función actual o viceversa), el orden en que se nombraban las posibles identidades del objeto (si se preguntaba ¿es una regadera o es una tetera?, o ¿es una tetera o un regadera?) o el tipo de objetos que se utilizaban en las historias (tetera/regadera, frisbee/plato, casco/tazón, coche/carrito de mercado) afectaba las decisiones de los participantes. Se encontró de manera significativa, que los adultos consideraban que el nombre que correspondía al objeto era aquel para lo cual había sido diseñado.

En el segundo experimento, se trabajó con niños entre los cuatro y seis años. Se encontró que los niños de cuatro años se guiaban menos por la función del diseñador que los niños de seis; en estos últimos la categorización estaba determinada por el para qué fue hecho el objeto. Por otro lado, el orden en que eran contadas las historias afectaba las decisiones de los niños de cuatro años.

En el tercer experimento, se trabajó con niños de cuatro años teniendo en cuenta que los de seis respondían de la misma forma que los adultos. En este se modificó el procedimiento de los anteriores experimentos para hacer más saliente la información sobre la función original y la actual. Para esto se usó una historia más elaborada, que enfatizaba en las intenciones del diseñador y los procesos de elaboración del artefacto. También se modificaron otros rasgos que aseguraban que el niño recordara la información relevante, como que los protagonistas eran de diferente sexo, además se mostraban imágenes que representaban de manera más explícita a los protagonistas y a las funciones relevantes de los artefactos. Se encontró que los cambios introducidos eliminaron los problemas de memoria que fueron característicos en el segundo experimento. Sin embargo, los niños de cuatro años todavía fallaban en la categorización de los artefactos de acuerdo a la función del diseñador.
Teniendo en cuenta los resultados de los tres experimentos, se concluyó que, primero, los adultos si tienen en cuenta la postura del diseño para tomar decisiones sobre los artefactos. En algunos casos, se observaba que la función pretendida interactuaba con los rasgos inferidos de los objetos, de tal manera que los adultos se ayudaban de éstos para tomar decisiones (por ejemplo, los adultos decían que el nombre del artefacto correspondía al para qué fue hecho, a menos de que los rasgos visuales se parecieran más a los de la función actual). Por el contrario, los niños de cuatro años casi no tuvieron en cuenta la función pretendida, por lo que se concluyó que ésta no organiza las decisiones de categorización de éstos niños. Esto podría deberse a que ellos todavía no han entendido la postura del diseño. Pero también, para Matan y Carey (2001), puede ser que los niños si entienden dicha postura pero los estudios fallan en capturarlo, de pronto porque los más jóvenes no han estructurado su entendimiento de los artefactos en los términos que aquí se presentaban. Los autores terminan defendiendo la primera posibilidad. Esto porque la evidencia sugiere que los niños dan peso a la forma sobre la función.

Además, porque cuando se les preguntaba a los niños para qué fue hecho el objeto, ellos no preferían la función pretendida sobre la actual. Esto está de acuerdo con otros estudios (German \& Johnson, 1997; Matan, 1997, citados por Matan \& Carey, 2001) en los que los niños muestran preferencia por la función actual sobre la función pretendida.

Una de las conclusiones interesantes, tanto del trabajo de Ameel y otros (2008) como el de Matan y Carey (2001) es que los niños pequeños prefieren la forma sobre la función, y que la progresiva incorporación de la función sería una característica propia del desarrollo. Mientras que los niños parecen tener una relación más directa con la forma, el para qué sirve y para qué fue diseñado un artefacto son informaciones que el niño empezaría a acoplar con el desarrollo a sus sistemas de categorías, hasta el pensamiento 
adulto. Posteriormente, desde otras perspectivas, veremos importantes conclusiones que enriquecerán este primer abordaje al desarrollo de la categorización.

\section{El futuro de la investigación en desarrollo de la categorización}

¿Cuál es el futuro de la investigación en desarrollo de categorización infantil? En la literatura encontramos que buena parte de las discusiones en categorización se enfocan en adultos y muy pocos en el desarrollo de la categorización (cf. las investigaciones señaladas por Cuenca \& Ruíz, 2004). Las dos investigaciones que se han señalado arriba con respecto al debate forma-función, son una muestra del interés creciente en el campo del desarrollo de la categorización. Todavía hay mucho camino que recorrer en esta temática, por ejemplo, queda todavía pendiente dar cuenta del papel de otros procesos cognitivos en el desarrollo de la categorización (en el trabajo de Matan y Carey se señala muy superficialmente el papel de la memoria, por ejemplo), y la relación entre categorización y la adquisición de la noción de permanencia de objeto (clave en el desarrollo según Piaget) a partir de rasgos perceptuales o funcionales.

De igual manera, nos planteamos hasta qué punto es viable tal debate entre forma-función, como si la categorización fuera producto de uno solo de esos procesos y no de la interacción de ambos. Del mismo modo, consideramos que una perspectiva que apoye una integración de la forma y la función, debería tener en cuenta que estos dos aspectos no necesariamente deberían explicar la categorización de todos los artefactos en la misma proporción; como si para categorizar cada artefacto del mundo tuviéramos en cuenta la forma en un $50 \%$ y la función en otro $50 \%$. No todas las categorías cumplirían con las mismas condiciones, si se tiene en cuenta que en el mundo nos encontramos con:

\footnotetext{
Artefactos con misma forma y nombre pero diferente función
}

Ej.: una taza o mug puede ser hecha para poner lápices, contener dulces o para tomar café.

Artefactos con la misma forma y función pero diferente nombre

Ej.: chuspa y bolsa, cubrelecho y cobertor.

Artefactos con diferente forma y nombre pero la misma función

Ej.: un butaco y una silla sirven para sentarse, un futón y una cama.

Artefactos con el mismo nombre y función pero diferente forma

Ej:: Salero, olla, silla, quesera.

Como vemos en estos ejemplos, cuando hablamos de función, se está entendiendo la función pretendida (y también la de uso) y a pesar de ello eso no se niegan las aparentes diferencias que pueden darse entre una misma función pretendida con los rasgos perceptuales y con el nombre de la categoría. Lo que pretendemos, con lo que veremos en el siguiente apartado, es que el debate forma-función debe ser trascendido para replantear el proceso de categorización no solo en la edad adulta sino cuando la pensamos en el desarrollo.

Otros problemas con la investigación en el desarrollo de la categorización son evidenciados por Oakes y Madole (2000). Ellas señalan que es necesario que la investigación en categorización se enfoque en la evaluación directa de la formación de las categorías infantiles. Según ellas, dos direcciones posibles de investigación serían, primero, acerca de cómo afectan las variaciones contextuales (como los efectos de la tareas y los estímulos) a la categorización infantil y, segundo, la evaluación de manera más directa de los tipos de información que los niños usan cuando forman categoría, así como el cambio en el uso de dicha información teniendo en cuenta la edad, las tareas, etc.

Respecto al primer caso, Oakes y Madole muestran evidencia que indica que la variación contextual afecta la categorización infantil. Por ejemplo, Quinn y otros (1993, citados por Oakes y Madole, 2000) realizaron experimentos con be-

Polisemia No. 12, 42 - 57, El desarrollo de la categorización: Perspectivas tradicionales y contemporáneas. Bogotá, ISSN: 1900-4648. Julio - Diciembre de 2011 
bés de tres y cuatro meses sobre diferenciación entre perros y gatos en un test de familiarización visual. En una primera fase del experimento (habituación), se les presentaba repetidamente a los bebés la imagen de un perro o de un gato. En una segunda fase (prueba), se les presentaba una imagen de un gato o perro diferentes al primero. Estos autores encontraron que los bebés que se habían familiarizado con imágenes de gatos en la fase de habituación atendían en mayor medida a una nueva imagen de un perro que de un gato en la fase de prueba. Mientras que, si a los bebés se les familiarizaba con perros, no se encontraban diferencias en las preferencias de atención hacia un nuevo gato o perro en la fase de prueba. Se infiere que si el bebé no atiende a la imagen novedosa significa que la considera idéntica a aquella con la cual se ha familiarizado, si por el contrario atiende a ella, se infiere que el bebé la considera diferente a la original. Así se concluía que los niños familiarizados con gatos respondían a una categoría exclusiva, es decir que incluía solo gatos. Por el contrario, los niños familiarizados con perros, respondían más a una categoría inclusiva, que incluía tanto a gatos como a perros. Los autores encontraron que esto se debía a que los perros de la familiarización tenían rasgos muy variables, por lo que se encontró que si estos rasgos se limitaban, la categoría se volvía exclusiva.

Otros experimentos han señalado que, dependiendo de la tarea, se propicia la creación de categorías específicas dependiendo de la fase de habituación (Quinn y otros, 1993; Roberts \& Cuff, 1989; Younger, 1990; Mandler \& McDonough, 1993; Oakes, Madole \& Cohen, 1991, citados por Oakes \& Madole, 2000). Otras tareas que no involucran fase de habituación pueden mostrar procesos de desarrollo en categorización. Por ejemplo, Madler y otros (1991, en Oakes \& Madole, 2000) encontraron que los niños de 18 meses distinguen entre animales y vehículos, pero que solo hasta los 24 a 30 meses distinguirán entre conejos y perros. Es un reto entonces entender la generalización de categorías sin tareas de habituación o fa- miliarización, o indagar si se puede extender a otros contextos lo que se ve en este tipo de tareas. Por ejemplo, se puede indagar si los niños que distinguieron entre vehículos y animales en una tarea de familiarización, pueden hacer tal distinción en otro tipo de tareas. En otros experimentos, por ejemplo, Oakes y otros encontraron que los niños de 10 meses diferenciaban animales de personas en una tarea de familiarización pero que esta distinción no se hacía en una tarea diferente (sequential-touching task, en Oakes \& Mandole, 2000, p. 122).

Por otra parte, Oakes y Mandole señalan que las tareas hacen diferentes demandas al niño (por ejemplo, en los números de objetos sobre los que debe dividir su atención, si debe recordar ejemplares sobre ensayos sucesivos y demás exigencias) (Oakes \& Mandole, 2000). Según las autoras, si se tiene en cuenta cómo estos aspectos de la tarea están influyendo en el desempeño del niño en determinada edad, se está avanzando en la investigación en torno al desarrollo infantil. Por ejemplo, tareas que difieran en demandas de atención y memoria pueden dar indicios de estos procesos en el desarrollo, y cómo afectan la categorización.

Otra dirección para la investigación sobre el proceso de categorización es evaluar directamente su formación en los niños, dando cuenta de las categorías específicas a las que ellos responden (como en Eimas, 1994; Mandler \& McDonough, 1993, citados por Oakes y Mandole, 2000) o también indagar cómo las categorías se forman, descubren o modifican en la sesión experimental (por ejemplo, en el caso de Quinn y otros). De todas maneras las autoras señalarán, siguiendo el trabajo de Thelen y Smith (1994) que la categorización es un proceso flexible, por lo que los resultados que arrojen las pruebas con niños en un momento determinado no deben tomarse como evidencia de una representación estable y rígida. La categorización varía en tanto que también lo hacen las condiciones contextuales y de la manera en que el niño se relaciona con los objetos. Estas posturas sobre categorización, desde lo que 
se llamará cognición corporizada, no solamente permitirán entender el papel del contexto y del desarrollo a varios niveles en la categorización, sino que nos ofrecerán un marco conceptual a partir del cual poner en duda la necesidad de un debate como el de forma-función. En lo que sigue, daremos cuenta de esta perspectiva.

\section{Explorando la cognición desde una visión situada y corporizada: Perspectiva que plantea nuevos problemas y soluciones al desarrollo de la categorización}

Esther Thelen y Linda Smith, en su más importante texto de 1994, plantearon nuevas maneras de abordar el desarrollo cognitivo que han posibilitado una postura crítica frente a las teorías tradicionales. No solamente buscaron alternativas a perspectivas del desarrollo basadas en estadios como la de Piaget, sino que también cuestionaron las teorías innatistas que todavía ocupan un lugar privilegiado en la explicación del desarrollo. Hacemos referencia a propuestas como la de Spelke (1998, citada en Scholl \& Leslie, 2003), Baillargeon (1992, citada por Thelen \& Smith, 1994), Wynn (1995), Melher \& Dupoux, (1994), y demás autores que desde investigaciones que parten de tareas con habituación o familiarización (como los que señalan Oakes \& Mandole, 2000) infieren que los bebés muy pequeños tienen conocimientos complejos, no solamente sobre la permanencia de los objetos (que para Piaget recién aparecían alrededor de los siete meses) sino sobre propiedades de éstos como la continuidad espaciotemporal, relación con un sonido y nociones aritméticas (Garavito \& Yañez, 2009).

Thelen y Smith (1994) dan explicación a los fenómenos encontrados por los innatistas, argumentando que el desarrollo cognitivo es producto de la interacción de múltiples subsistemas que involucran el cerebro, el cuerpo y el entorno. Estos tres sistemas se ubican al mismo nivel, con lo cual se niega el neurocetrismo que explica el desarrollo como producto exclusivo de la madu- ración de zonas cerebrales, específicamente de regiones corticales (Munakata et al., 1997, citados por Thelen et al., 2001; Pushina, Orekhova \& Stroganova, 2005). Del mismo modo, se busca superar el dualismo entre los procesos cognitivos y los procesos sensorio-motores, para decir en últimas que ambos son lo mismo, en tanto que la cognición es un producto emergente de la relación de un cuerpo y su sistema nervioso con el entorno. Con esto, lo mental deja de verse como amodal, proposicional y composicional (Smith \& Sheya, 2010), para involucrar los procesos relevantes a la percepción y a la acción ¿cómo entender la categorización desde estas perspectivas? Para hacer un acercamiento a este problema, abordaremos primero en términos generales la propuesta del desarrollo cognitivo, para posteriormente, acercarnos al desarrollo de la categorización desde estas perspectivas.

\section{La "cognición" desde la visión tradicional no explica la cognición}

Para Smith y Sheya (2010), las teorías tradicionales de la cognición han tenido un profundo impacto en el estudio del desarrollo. Este se ha enfocado en la competencia y los conceptos, dejando de lado los procesos de desempeño. Con esto a su vez se deja de lado una perspectiva en la que el aprendizaje y el desarrollo se reconozcan como producto de eventos que ocurren en tiempo real y los cuales involucran el actuar y el percibir en el mundo.

Para ilustrar esta propuesta, se pone como ejemplo a Piaget, quien propuso una visión que integraba la cognición con procesos no cognitivos. Por ejemplo, cuando planteó la "reacción circular primaria", como uno de los procesos que explicaban del desarrollo sensoriomotor. Esta reacción explica que el bebé repita conductas debido a la excitación que le produjo la primera vez que la realizó de forma accidental. Por ejemplo, cuando un bebé mueve un sonajero, este entra y sale de su campo visual a la vez que emite un sonido, lo que produce excitación; esta produce más 
movimientos corporales que terminan haciendo que el sonajero se mueva más rápido dentro y fuera del campo perceptual y genere más ruido. Si bien el bebé tiene poco control sobre la mano y el ojo, esos minutos de actividad que envuelven bucles de percepción y acción, eran para Piaget el origen de la inteligencia. Actualmente se ha identificado que esos bucles de actividad generan cambio neuronal y conectividad (Lungarella, Pegors, Bulwinkle \& Sporns, 2005; Lungarella \& Sporns, 2006; McIntosh, Fitzpatrick \& Friston, 2001; Metta y Fitzpatrick, 2003; Tononi, 2004 en Smith \& Sheya, 2010). Esta idea de reacción circular muestra que sistemas heterogéneos (que involucran distintos sistemas perceptuales y motores), cuando se acoplan en un una tarea, crean un sistema complejo dinámico que aprende por sí mismo, lo que termina generando regularidades que cambian las propiedades internas de los sistemas y sus conexiones (Smith \& Sheya, 2010). Cada sistema está conectado con los otros y por ende un patrón de activación de un sistema en un momento dado (en el ejemplo anterior, la visión) depende tanto del input, de sus estado previo y de los estados previos de otros sistemas (como el auditivo o el motor). Ejemplos de este proceso se presentan, desde esta postura de sistemas, con respecto a la noción de objeto (Smith, Thelen, Titzer \& McLin, 1999; Thelen, Schöner, Scheier \& Smith, 2001) perspectiva y profundidad (Adolph \& Joh, 2007) y el reconocimiento de letras (James, 2009, citado por Smith \& Sheya, 2010).

También la categorización involucra estos acoplamientos y modificaciones en sistemas que interactúan constantemente. Por ejemplo, Smith (2005) da cuenta de cómo la percepción de la forma de los objetos, que posibilita la categorización, no es algo dado de antemano sino que es producto del desarrollo. En este proceso, en tanto el sistema perceptivo se acopla con el motor, podemos decir que la acción con los objetos modifica la percepción y por ende los rasgos que el niño tiene en cuenta para categorizar. Por su parte, Sheya \& Smith (2006), afirman que el aprendizaje de categorías no implica el aprendi- zaje de rasgos o propiedades aisladas, sino que lo que el niño aprende son sistemas de conocimiento de rasgos que aparentemente no tienen una relación entre sí.

\section{La forma es producto del desarrollo}

En las teorías que defienden la forma como Ameel y otros (2008), se ha indicado que durante el desarrollo y en la edad adulta, los rasgos perceptuales que tenemos en cuenta para categorizar un objeto no son los mismos. Se ha visto por ejemplo, que alrededor de los 12 meses, cuando comienza el niño a desarrollar el lenguaje, tiende a cometer error de generalización, como llamar a todos los vehículos de trasporte "carro". Por medio de estudios se encuentra que la generalización de un nombre escuchado aumenta de los 13 a 18 meses, pero se corrige con el tiempo. ¿Cuál es el proceso mediante el cual los rasgos comienzan a variar? Smith (2005) plantea que este proceso está relacionado con variaciones en la forma percibida de los objetos, variaciones que claramente afectan la categorización. Dichos cambios en la percepción, no tiene que ver con una maduración a nivel del los órganos de los sentidos o a nivel neuronal, antes bien, es a través de la experiencia que dichos cambios comienzan a darse. Con esto se está de acuerdo con la propuesta de cognición situada, de que la acción con los objetos afecta la percepción de ellos, lo que en últimas termina afectando procesos cognitivos como la categorización.

Para entender el proceso de categorización, Smith lo liga a la acción con los objetos que sucede en las primeras etapas del desarrollo. Por eso, da cuenta del juego en los niños pequeños. Los niños de doce meses, por ejemplo, al mismo tiempo que comienzan a hablar, muestran cambios en la manera en que juegan con los objetos. Se observa en ellos un reconocimiento de categorías debido a la manera en que actúan con los objetos (como hacer ruidos de sorber con una taza de juguete o usar un peine de juguete para peinarse su propio cabello). Luego, 
estas acciones estarán dirigidas a los juguetes (peinar a la muñeca, hacer el gesto de dar de beber al osito de peluche); esto se llamará juego pretendido, mediante el cual el niño hace acciones claras de categorías bien definidas. A los 18 y 24 meses, el niño incluye el juego simbólico. En este, los objetos con las formas más simples son usados para desempeñar acciones de categorías de la vida cotidiana. Así, un banano puede ser un teléfono, o una caja puede ser una cuna. Para Smith, en este caso sucede que el niño comienza a separar rasgos específicos de los objetos y emparejarlos con los de otros, lo que lleva al juego. Pero además, Smith sugerirá que es la misma acción con los objetos lo que permite evidenciar rasgos específicos que se pueden emparejar con los de otros objetos. Manipular la caja hace verla como una posible cama de la muñeca; en la manipulación del banano, la manera en que se puede agarrar y el tamaño, hacen posible usarlo como un teléfono.

Esta propuesta se convierte en una alternativa al debate forma-función, que no ha reparado en la posibilidad de que la acción modifique la percepción y que esto posibilite la formación de categorías. Esta interacción acción/percepción no sería lineal, ya que la formación de categorías a partir de la forma modificada, también altera futuras acciones con los objetos. Una categoría entonces, no será una propiedad representacional, fija, sino producto de un proceso de abstracción que se da como consecuencia de múltiples interacciones con los objetos de las categorías, donde la acción y la percepción se van modificando y actualizando siempre.

Para dar cuenta de esta relación entre percepción y acción, Smith presenta una serie de experimentos. En el primero, se divide a niños de 18 a 24 meses según la magnitud de su vocabulario funcional. Así se crean dos grupos, los que tienen un repertorio de menos de 100 palabras, $y$ los que tienen entre 100 y 200 palabras. A estos niños se les puso a jugar con objetos de plástico con rasgos muy poco definidos, y se les pidió que jugaran de diferentes maneras: con unos objetos que tenían forma triangular se les instó a jugar como si fueran un trozo de pizza (que lo agarraran igual que una pizza y se lo llevaran a la boca) y con unos con forma rectangular a que jugaran como si fuera una cámara (agarrarlo como una cámara y hacer como si tomaran fotos). También se les dieron objetos con los rasgos típicos de estas categorías (una cámara de juguete y un pedazo de pizza de juguete). Luego se preguntaba a los niños qué eran los objetos: mientras que todos los niños identificaban la categoría del objeto que tenía los rasgos típicos, en el caso de los objetos simples el grupo que tenía menos de 100 palabras en su repertorio no identificaba el juguete pero el de más de 100 sí lo hacía.

Lo anterior indicó que la primera fase de adquisición de palabras ya supone el reconocimiento de rasgos de las cosas comunes, pero que solamente después, junto con el juego simbólico, es decir con la acción con objetos que inicialmente no serían de la misma categoría, la forma percibida se va modificando, haciéndose más especializada y creando abstracciones de las formas de los objetos, lo que servirá para la categorización de objetos con los que el niño interactuará en su vida, en donde como dijimos antes, dicha abstracción se va modificando.

Pero el reconocimiento de la forma relevante para categorizar un objeto, no parece solamente afectar los casos de objetos conocidos sino también los objetos novedosos. En otro experimento, a niños de la misma condición del primer experimento, se les presentaba un objeto novedoso y se les decía su nombre: "alcachofa". Luego se les presentaban tres caricaturas de la alcachofa, entre las cuales una tenía la misma forma de la alcachofa original. Se les preguntaba a los niños ¿cuál es la alcachofa? Se identificó igualmente, que los niños de menos de 100 palabras en su repertorio se equivocaban, mientras que los de más de 100 no, escogiendo la caricatura que se asemejaba a una alcachofa. Con esto se confirmó la predicción de que la habilidad de reconocer las formas adecuadas es una experticia capaz de ser extendida hacia otros objetos. 
En los experimentos tres y cuatro, se buscó probar la hipótesis de que la acción modifica la percepción y en últimas la categorización de los objetos. En estos experimentos, se presentaban objetos realizados en el laboratorio, con una forma novedosa, y se les presentaba a los niños diciéndoles "esto es un zup". Frente a la mitad de los niños (entre los dos y tres años) el experimentador realizaba una actividad con el objeto (como sacudirlo con una sola mano) y con la otra mitad realizaba otra actividad (como rotarlo con las dos manos). Se instaba al niño a jugar con el objeto de esa manera. Posteriormente se le pedía a los niños que, entre una serie de objetos, se escogiera cueles eran también zups. Efectivamente se encontró que la acción que los niños realizaban determinaba los objetos que escogía como pertenecientes a la categoría, pues cada grupo de niños escogió diferentes objetos como parte de la categoría; se encontró que ellos tenían en cuenta para estos ciertos rasgos que eran relevantes al realizar una acción y no la otra.

Los resultados de los experimentos permiten para Smith hacer una teoría del desarrollo de la categorización. Los dos primeros experimentos mostrarían que la percepción de la forma cambia en el desarrollo, específicamente entre los 18 y 24 meses. Los niños progresan en la generalización, tanto de las acciones como de los nombres de los objetos. Los experimentos 3 y 4 indican que las acciones influencian la percepción de la forma, estando ésta en función de la acción. Esto es un avance en el entendimiento del proceso mediante el cual damos cuenta del mundo, lo cual no estaría desligado de nuestra acción en él.

El desarrollo supone mayor experiencia y la abstracción de las formas va siendo cada vez más compleja. También esta propuesta nos permite entender que las categorías son flexibles, siempre es posible que se puedan modificar; así podemos entender que en la vida cotidiana podemos hacer categorías transitorias para propósitos específicos como "las cosas que en mi mesa sirven para matar una mosca". En este caso, los rasgos necesarios para la categoría serán distintos a los que se usan cotidianamente. Esto dependerá de las acciones que hemos tenido con los objetos, en donde el proceso de abstracción de rasgos toma otro rumbo, teniendo en cuenta aspectos como la dureza, flexibilidad, o tamaño, que aunque no son relevantes para una categoría, pueden servir para otra.

La relación entre acción y percepción va tener un giro particular en Sheya y Smith (2006) quienes se enfocan en mostrar que esos rasgos que nos permiten categorizar no son aislados, sino que pertenecen a sistemas de conocimiento en los cuales dichos rasgos se van afectando mutuamente.

\section{Sistemas de conocimiento en la categorización}

Sheya y Smith encuentran que aprender categorías involucra el aprendizaje de sistemas de conocimiento. Por ejemplo, sistemas que incluyen relaciones entre propiedades (cada cosa que tiene ojos tiene boca o tiene pelo), relaciones entre propiedades y roles (las cosas que tienen ruedas se mueven, o las cosas que tienen boca se mueven), y relaciones entre roles (las cosas que duermen se mueven, las cosas que pitan se mueven). Inicialmente la relación propiedad-rol es directa (las cosas con boca comen) pero con la experiencia, estas relaciones no necesariamente son directas (las cosas con boca duermen). Parecería que los sistemas se van complejizando con el desarrollo, involucrando cada vez más relaciones entre propiedades y roles. Por ejemplo, se ha encontrado que al categorizar, los niños más pequeños (entre dos y tres años) tienen en cuenta mínimo dos de las propiedades de los objetos, y a su vez la relación de estas propiedades con un rol. Pero no hay mucha evidencia de que la categorización de estos niños dependa solamente de los roles o funciones del objeto.

Sheya y Smith (2006) presentan tres experimentos con niños de dos años (la edad en que inicia el aprendizaje de conceptos), de tres años 
(la edad en que se da una "explosión", un aumento significativo en el aprendizaje de conceptos), y de cinco años (niños en los que el aprendizaje es estable). En estos tres experimentos se buscaba identificar las relaciones que los niños hacían entre propiedades, roles o propiedades y roles en el momento de categorizar.

En el primer experimento, se mostraba a niños de estas tres edades, acciones que corresponden a animales o vehículos (alimentarlos, moverlos con sonidos como chuии-chuи, etc.), con objetos que no tenían ninguna de las propiedades típicas de animales o vehículos (una especie de estrella, una en forma ovoide o una en forma de salchicha). Se les pedía que repitieran dichas acciones y se les preguntaba posteriormente en qué lugar irían dichos objetos (si en un establo o en una estación de gasolina). Se encontró que mientras que los niños de dos y tres años se confundían, los de cinco años respondían bien a la tarea, haciendo inferencia de la categoría a la que pertenecían los objetos a partir de los roles, sin ninguna ayuda perceptual.

En un segundo experimento, se trabajó con niños de dos y tres años. Teniendo en cuenta evidencia de Butterworth (1998, en Sheya \& Smith, 2006) los niños de estas edades atendían a pequeños grupos de rasgos perceptuales en el momento de categorizar, por lo que se quería identificar si algunos rasgos típicos de los objetos podían ayudar a que el niño identificara la categoría. Así se hizo el mismo experimento anterior, solo que a los objetos se les añadieron llantas u ojos y con algunos sujetos los experimentadores mostraban un rol específico mientras que con otros no. Se encontró que los niños de tres años ubicaban correctamente el objeto en esta condición, ya se hubiera o no demostrado la acción con el objeto. Por lo tanto, parecía que el niño de tres años no necesitara del rol para identificar la categoría. Los niños de dos años tampoco pudieron identificar la categoría en este experimento.

Los autores se preguntan si la dificultad de los niños de dos años se debe a su incapacidad de hacer relaciones rol-rol o propiedad-rol, o tal vez porque necesitan más soportes perceptuales que los otros niños en el momento de categorizar. En el tercer experimento, se trabajó con niños de dos años; en este caso los objetos estaban ricamente detallados y había dos situaciones, una en que se demostraba la acción y otra en la que no. Efectivamente, los niños lograban ubicar correctamente los objetos en las situaciones en que se demostraba la acción y en las que no, uniendo los roles que se sugerían en los dos escenarios (establo o estación de gasolina). Pero aquí se sugiere que no hay evidencia de que los niños sepan algo sobre correspondencia entre diferentes roles. Ya que los niños se desempeñaban bien en los casos en que había información y en los que no había, parece que en ambas condiciones lo que se usan son propiedades perceptuales para escoger el escenario adecuado.

Se propone que dos procesos pueden subyacer este desempeño de los niños de dos años. Primero, ya que los objetos eran conocidos y bien detallados, puede pasar que los niños primero reconocían los objetos como ejemplos de categorías conocidas y luego, a través de la categoría, ligaban el objeto al rol, o segundo, ya que estos objetos tenían muchos rasgos que predecían roles, puede ser que las llantas y ojos no fueran suficientes para unir el objeto al rol pero sí grupos más amplios de rasgos. Para dar cuenta de cuál de estos procesos subyacía, se realizó un cuarto experimento, en el que se incluían cuatro tipos distintos de juguetes: a) objetos novedosos sin rasgos predictivos como en el primer experimento; b) objetos novedosos con solo un rasgo predictivo, como en el segundo experimento; c) objetos no familiares con un grupo de rasgos predictivos (nuevo estímulo) y d) objetos familiares con muchos rasgos predictivos, como en el tercer experimento. En cada condición se demostraba un rol y se le pedía al niño que diera cuenta de un rol diferente de dicho objeto. Los autores encontraron que con el objeto bien detallado y con el objeto desconocido que tenía un grupo de rasgos perceptuales, los niños ubicaron los objetos de acuerdo a lo esperado, mientras que en las condi-

Polisemia No. 12, 42 - 57, El desarrollo de la categorización: Perspectivas tradicionales y contemporáneas. Bogotá, ISSN: 1900-4648. Julio - Diciembre de 2011 
ciones a) y b) el desempeño fue negativo. Por lo tanto, se concluye que los niños de dos años tienen en cuenta grupos de rasgos perceptuales en el momento de categorizar y que la extensión de las categorías dependerá de la semejanza dentro de ese grupo de rasgos.

Teniendo en cuenta los resultados de la investigación, se concluyó que progresivamente los niños necesitan menos cantidad de propiedades para identificar el rol de un objeto. Por otra parte, estos resultados evidencian que la categorización involucra sistemas de conocimiento que se van desarrollando con el tiempo y con la experiencia en la categorización de objetos, por lo que cada vez se necesita de menos información para tener al alcance todo el sistema completo, que identifica un objeto con una categoría. Esto se relaciona con el hecho de que un rol determinado con el tiempo va estando ligado a otros roles y a propiedades con las cuales aparentemente no se relaciona directamente, aunque si hacen parte del sistema en su totalidad.

Inicialmente, la dependencia de los rasgos perceptuales es un buen comienzo para identificar un objeto dentro de una categoría. A diferencia de otra literatura en desarrollo cognitivo, que considera que esa dependencia perceptual es evidencia de una solución no conceptual a problemas cognitivos (Madole \& Oakes, 1999, en Sheya \& Smith, 2006), aquí se sugerirá una visión alternativa en la que en el conocimiento conceptual de cualquier tipo no es fácil para el niño pequeño a menos de que se traiga a colación en tareas específicas en tiempo real. Así las tareas en tiempo real que involucran propiedades perceptuales de los objetos reales son partes esenciales del sistema conceptual, ya que estas son las que terminan llevando al mundo conceptual al niño. En otra investigación (Sheya, Haniana \& Demir, 2004 en Sheya \& Smith, 2010) se hizo una serie de experimentos con adultos, en las que los resultados indican que el sistema de aprendizaje de relaciones entre roles, va a requerir siempre unas claves perceptuales que sirvan como vinculante; una vez que las relaciones se han aprendido, las claves perceptuales se vuelven obsoletas. Por lo tanto, Sheya y Smith concluirán que la función de los rasgos perceptuales puede ser una característica propia del sistema conceptual humano y no solo de los niños pequeños.

\section{Conclusiones}

En este texto hemos hecho un recuento de diferentes teorías que han buscado, dentro de la psicología, dar cuenta del desarrollo de la categorización. Encontramos que principalmente la investigación se enfoca en la categorización de artefactos, aunque en investigaciones como la de Sheya y Smith se involucren otras entidades como seres vivientes. Lo que encontramos con esta revisión teórica es que por un lado, las versiones tradicionales de la categorización terminan volviéndose exclusivistas al darle predominancia a la forma o a la función en la categorización. Y que, como una posición alternativa, las perspectivas desde cognición corporizada se enfocan en cómo el aprendizaje de categorías depende de una experiencia con los objetos y con los conceptos, en donde progresivamente el niño va haciéndose más experto en reconocer las claves perceptuales que hacen que un objeto se pueda ubicar en una categoría.

Lo primero que uno pensaría es que esta propuesta no se diferencia de las teorías clásicas que ven también como el niño va progresivamente teniendo en cuenta los mismos rasgos que los adultos en la categorización. Sin embargo, en una lectura cuidadosa, encontramos diferencias sustanciales entre una y otra postura: mientras que unas se enfocan en el problema de si los rasgos que tenemos en cuenta son meramente perceptuales o funcionales, a la otra le interesa es más el papel de la acción en la modificación de la percepción, y en fin, el reconocimiento de que la categorización es finalmente un proceso sensorio-motor, en el que la experiencia con los objetos (en tanto que los reconocemos chupándolos, agarrándolos, rodeándolos, etc.) es lo que nos hace a la vez expertos en identificar la categoría. Sabemos que un objeto es una si- 
lla porque hemos interactuado con muchas de ellas, sentándonos, rodeándolas, moviéndolas, etc., y estas acciones han determinado los rasgos perceptuales que tenemos en cuenta para decir que ese objeto es una silla, rasgos que seleccionamos por encima de muchos otros que los están acompañando. Así, cuando vemos un objeto inicialmente desconocido, basta relacionarlo en nuestras experiencias pasadas con objetos semejantes, identificar las claves perceptuales y decir "esto es una silla". Para hacerlo, la única condición es la experiencia sensorio-motora, apoyada de una experiencia con el mundo lexical en el que otros me han ido indicando si mis categorías iban por buen camino o no (o sino miremos a los padres, hermanos, y profesores corrigiendo a los niños pequeños cuando una categoría está mal ubicada).

Lo que nos presentan autores como Thelen y Smith (1994) es que estas perspectivas desde la cognición situada y corporizada, enfatizan finalmente una visión piagetiana del niño, en el que se demarca el desarrollo mental a través de las percepciones y las acciones en el universo práctico que rodea al niño pequeño. A partir de allí la representación, entendida aquí como la imagen prototípica del mundo que se ha considerado la base de cualquier categorización (como el modelo a partir del cual comparamos los objetos con los que nos topamos), deja de ser la explicación de la manera en que categorizamos. Tradicionalmente se habían reconocido por se- parado los procesos cognitivos de los sensoriomotores debido a que éstos últimos se relacionan con el percibir y actuar que involucran el cuerpo, mientras que la cognición implicaba cómo la información es representada y transformada en la mente, como producto de una actividad neurológica del encéfalo y del sistema nervioso central. Las perspectivas que aquí abordamos dirán que la cognición está determinada por el conjunto de memorias relacionadas con nuestra experiencia sensorio-motora, lo cual incluye, tanto la inteligencia infantil como en general la inteligencia humana. Reconocemos que esta teoría está aún en sus comienzos, pero es un paso interesante al entendimiento de la cognición en general que está teniendo en la actualidad cada vez más adeptos, con unos aportes interesantes que vale la pena no descartar.

Entre las preguntas que nos planteamos respecto a esta teoría de la categorización está cómo la explicación de la categorización de artefactos y clases naturales puede ser extrapolada a otro tipo de categorías, como las morales por ejemplo. Desde la teoría de cognición situada y corporizada, la moralidad se podría entender como un sistema de conocimiento distinto a otros en los cuales nos desenvolvemos, que involucra también la acción y la percepción que se modifica por ella. De esta manera, las categorías morales deberían estar enraizadas en los mismos procesos que se han adjudicado a las de artefactos, sin embargo, todavía es un problema que se debe abordar. 


\section{Referencias bibliográficas}

Adolph, K. E y Joh, A. S. (2007). Motor Development: How infants get into the act. En A. Slater, y M. Lewis (Eds). Infant development. New York: Oxford University Press. Recuperado en diciembre 1 de 2010 disponible en http://www.psych.nyu.edu/ adolph/PDFs/SlaterChapter.pdf

Ameel, E., Malt, B. y Storms, G., (2008). Object naming and later lexical development: from baby bottle to beer bottle, Journal of Memory and Language, 58, 262-285.

Bloom, P., (2007). More than words: a reply to Malt and Sloman. Cognition, 105, 649-655.

Cuenca A. y Ruíz L. (2004). ¿Cuál es el criterio que tenemos en cuenta cuando asignamos nombres y funciones a los artefactos? Tesis de grado para aspirar a título de psicóloga. Universidad Nacional de Colombia.

Garavito, M. y Yáñez, J. (2009). La construcción del espacio y de los objetos desde la perspectiva de los sistemas dinámicos. En Grupo Complexus (ed.). Gestión del conocimiento. Grupos de investigación. Bogotá: Universidad Nacional de Colombia.

Malt, B. y Slogan, S. (2007). More than words, but still not categorization. Cognition, 105, 656-657.

Matan, A. y Carey, S. (2001). Developmental changes within the core of artifact concepts. Cognition, 78, 1-26.

Oakes, L. y Madole, K. (2000). The Future of infant categorization research: A processoriented approach. Child Development, 71(1), 119-126.

Piaget, J. (1961). La formación del símbolo en el niño. México: Fondo de Cultura Económica.

(1972). El nacimiento de la inteligencia en el niño. Barcelona: Aguilar.
(1979). La construcción de lo real en el niño.

Buenos Aires: Nueva Visión.

Pushina, N. N., Orekhova, E. V. \& Stroganova T. A. (2005) Age-Related and individual differences in the performance of a delayed response task (the A-not-B task) in infant twins aged 7-12 months. Neuroscience and Behavioral Physiology, 35, (5), 481-490.

Thelen, E., Smith, L. B. (1994). A dynamic systems approach to the development of cognition and action. Cambridge. The MIT Press.

Scholl, B. J. y Leslie, A. M. (2003). Explicación del concepto de objeto en el infante: más allá de la dicotomía de la percepción y la cognición. En E. Lepore y Pylyshyn (Eds.), ¿Qué es la ciencia cognitiva? (pp. 30-88). México: Oxford University Press.

Sheya, A. y Smith, L. B. (2006). Perceptual features and the development of conceptual knowledge. Journal of Cognition and Development, 7 (4), 455-476.

Smith, L. B. (2005). Shape: a developmental product. En: Carlson L. y Van der Zee (eds). Funtional features in language and space. Oxford University Press.

Smith, L. B. y Sheya, A. (2010). Is cognition enough to explain cognitive development? Topics in Cognitive Science 1-11.

Smith, L. B., Thelen E., Titzer R. \& McLin (1999). Knowing in the context of acting: The task dynamics of the A-not-B error. Psychological Review, 106 (2), 235-260.

Thelen, E., Schöner, G., Scheier, C. \& Smith, L. (2001). The dynamics of embodiment: A field theory of infant perseverative reaching. Behavioral and brain sciences, 24 (1), 1-86.

Wynn, K. (1995). Infants possess a system of numerical knowledge. Current Directions in Psychological Science, 6 (4), 172-177. 